\title{
Bestuursverslag en Assurance
}

\section{Hans Gortemaker}

\begin{abstract}
SAMENVATTING De betrokkenheid van de accountant bij het bestuursverslag (nieuwe term voor jaarverslag) was voorheen beperkt tot de zogenoemde aanwezigheidsen consistentietoets. Door het van kracht worden van de Uitvoeringswet richtlijn jaarrekening moet de accountant nu nagaan of het bestuursverslag, in het licht van de tijdens de controle van de jaarrekening verkregen kennis en begrip omtrent de rechtspersoon en zijn omgeving, materiële onjuistheden bevat. Op grond van de huidige wet- en regelgeving behoeft geen assurance bij het bestuursverslag te worden gegeven.

Toekomstige ontwikkelingen gaan duidelijk verder. Diverse stakeholders pleiten voor een vorm van zekerheid bij het bestuursverslag. Hierbij verdient het niveau van zekerheid en de daarbij behorende formulering aandacht.

Een aantal (grote) ondernemingen laat reeds op vrijwillige basis assurance verschaffen aan informatie opgenomen in de jaarverslaggeving naast de controle van de jaarrekening.
\end{abstract}

\section{RELEVANTIE VOOR DE PRAKTIJK Het bestuursverslag neemt een steeds belang-} rijkere plaats in. Op basis van wet- en regelgeving, maar ook op grond van codes moet meer financiële en niet-financiële informatie in het verslag worden opgenomen. Ook ontwikkelingen op het gebied van integrated reporting doen het belang van informatie, naast informatie die is opgenomen in de jaarrekening, toenemen. Door wet- en regelgeving neemt de betrokkenheid van de accountant bij het bestuursverslag toe. Op vrijwillige basis is reeds sprake van het verschaffen van assurance bij het bestuursverslag. Het artikel beoogt stakeholders en accountants op de hoogte te brengen van de huidige en toekomstige ontwikkelingen.

\section{Inleiding}

In dit artikel staat de betrokkenheid van de accountant bij het bestuursverslag centraal. Eerst wordt in paragraaf 2 ingegaan op de eisen waaraan het bestuursverslag dient te voldoen. Aangezien het verschaffen van zekerheid bij het bestuursverslag in deze bijdrage een belangrijke plaats inneemt, wordt in paragraaf 3 aan het begrip assurance aandacht geschonken. De huidige betrokkenheid van de accountant bij het bestuursverslag komt in paragraaf 4 aan de orde, waar overigens al een verbinding naar de toekomstige betrokkenheid (paragraaf 5) wordt gelegd. In de daarop volgende paragraaf wordt kort stilgestaan bij de huidige praktijk, waarna een slotbeschouwing volgt.

\section{Het bestuursverslag}

De jaarlijkse verslaggeving bestaat uit de jaarrekening, het bestuursverslag en de overige gegevens. De wettelijke bepaling inzake het bestuursverslag is opgenomen in artikel 2:391 lid 2 BW. Volgens de wettekst (beknopt weergegeven) geeft het bestuursverslag een getrouw beeld van de toestand op de balansdatum, de ontwikkelingen gedurende het boekjaar, en van de resultaten. Indien noodzakelijk voor een goed begrip omvat de analyse zowel financiële als niet-financiële prestatie-indicatoren, met inbegrip van milieu- en personeelsaangelegenheden. Tevens wordt een beschrijving gegeven van de voornaamste risico's en onzekerheden. In het verslag wordt omtrent de verwachte gang van zaken met name aandacht besteed aan investeringen, de financiering, de personeelsbezetting en omstandigheden waarvan de ontwikkeling van de omzet en rentabiliteit afhankelijk is. Voorts worden mededelingen gedaan omtrent onderzoek en ontwikkeling. Vermeld wordt de invloed op de verwachtingen van bijzondere gebeurtenissen, waarmee in de jaarrekening geen rekening behoeft te worden gehouden. Ten aanzien van het gebruik van financiële instrumenten worden doelstelling en beleid inzake risicobeheer vermeld.

Het bestuursverslag mag niet in strijd zijn met de jaarrekening. Bij algemene maatregel van bestuur kunnen nadere voorschriften worden gesteld aan de inhoud van het verslag. Een voorbeeld hiervan is het Besluit Corporate Governance .

Een nadere uiteenzetting omtrent de inhoud van het bestuursverslag is te vinden in de Richtlijnen voor de jaarverslaggeving (Raad voor de Jaarverslaggeving, 2015). Een uitgebreide beschouwing over het bestuursverslag is verschenen van de hand van Knoops (2004). Voor beursgenoteerde vennootschappen geeft de Nederlandse Corporate Governance Code (2008) invulling aan te stellen eisen voor het bestuursverslag. De Monitoring Commissie Corporate Governance Code (2016) heeft voorstellen tot herziening ingediend. Ook in andere sectoren zijn codes voorhanden, waarin onder meer bepalingen inzake het bestuursverslag zijn opgenomen.

Een belangrijke ontwikkeling op het gebied van verslaggeving betreft Integrated Reporting. Hierbij staat het waardecreatieproces van de huishouding centraal. Financiële en niet-financiële informatie over doelen, strategie, governance, kansen en risico's, mede toe- 
komstgericht en gerelateerd aan "het kapitaal" van de huishouding geven "het verhaal" van de huishouding weer. Niet alleen de component financial, maar ook de overige "kapitalen": manufactured, intellectual, human, social and relationship, alsmede natural worden gevolgd tijdens het waardecreatieproces binnen de huishouding. Het International Integrated Framework (IIRC, 2013) geeft hier nadere invulling aan.

In dit artikel zal evenwel de nadruk liggen op het bestuursverslag, zoals bedoeld in de Nederlandse wet- en regelgeving.

\section{Assurance}

De begrippenlijst van de Nadere voorschriften controle- en overige standaarden (NV COS, 2016) omschrijft een assurance-opdracht als een professionele dienst waarbij de accountant een conclusie formuleert die beoogt het vertrouwen van de gebruiker, niet zijnde de verantwoordelijke partij, in de uitkomst van de evaluatie of de toetsing van het object van onderzoek ten opzichte van de van toepassing zijnde criteria te versterken. Onder het brede begrip assurance vallen de controle of beoordeling van historische financiële informatie en de overige assurance-opdrachten.

Hierbij worden twee niveaus van zekerheid onderscheiden: een redelijke mate van zekerheid en een beperkte mate van zekerheid.

Een voorbeeld van de controle van historische financiele informatie is de (wettelijke) controle van de jaarrekening. Voorbeelden van overige assurance-opdrachten, waar reeds standaarden voor bestaan, zijn onderzoeken gericht op: toekomstgerichte financiële informatie, interne beheersingsmaatregelen bij een serviceorganisatie, emissieverslagen, pro forma financiële informatie, maatschappelijke verslagen en prospectussen.

\section{Huidige rol van de accountant en het bestuurs- verslag}

Tot voor kort was de betrokkenheid van de accountant bij het bestuursverslag beperkt tot de zogenoemde aanwezigheids- en consistentietoets. Artikel 2:393 lid 3 BW gaf aan dat de accountant na moest gaan: "of het jaarverslag, voor zover hij dat kan beoordelen, overeenkomstig deze titel is opgesteld en met de jaarrekening verenigbaar is". Tevens moet conform het Vaststellingsbesluit nadere voorschriften inhoud bestuursverslag de accountant ook de mededeling en de gegevens die in artikel $3 \mathrm{a}$ onder a en artikel $3 \mathrm{~b}$ in de verklaring inzake corporate governance worden opgenomen in zijn onderzoek betrekken. Ten aanzien van de overige mededelingen, genoemd in artikel $2 \mathrm{a}$ van het Vaststellingsbesluit, gaat de accountant na of zij zijn opgenomen. Deze mededelingen hebben betrekking op de informatie die de naamloze vennootschap in de zogenoemde corporate governance-verklaring moet opnemen.
De Uitvoeringswet richtlijn jaarrekening is 1 november 2015 van kracht geworden. Op grond hiervan is artikel 2:393 lid 3 BW aangepast. Het begrip jaarverslag is vervangen door bestuursverslag en de passage: "voor zover hij dat kan beoordelen" is geschrapt. Belangrijk is de toevoeging dat de accountant moet nagaan "of het bestuursverslag in het licht van de tijdens het onderzoek van de jaarrekening verkregen kennis en begrip omtrent de rechtspersoon en zijn omgeving, materiële onjuistheden bevat". De accountantsverklaring omvat een oordeel hieromtrent, onder opgave van de aard van die onjuistheden. De reikwijdte van de toevoeging moet niet worden onderschat, als in aanmerking wordt genomen wat standaard 315 (NV COS, 2016) eist van de accountant met betrekking tot het vereiste inzicht in de entiteit en haar omgeving, met inbegrip van haar interne beheersing (beknopt weergegeven):

- relevante sectorspecifieke factoren, regelgeving en andere externe factoren;

- de aard van de entiteit: activiteiten, eigendoms- en governancestructuur, investeringen, de wijze waarop de entiteit is gestructureerd en financiering;

- keuze waarderingsgrondslagen, doelstellingen en strategieën, bedrijfsrisico's, die tot risico's op een afwijking van materieel belang kunnen leiden;

- de wijze waarop de entiteit haar financiële prestaties meet en beoordeelt;

- de interne beheersing, die relevant is voor de controle;

- het voor de financiële verslaggeving relevante informatiesysteem.

Dit gaat belangrijk verder dan de tot dan toe uitgevoerde aanwezigheids- en consistentietoets. De accountant past bij de controleaanpak zijn kennis van de sector en de huishouding toe om risico's van materieel belang te identificeren. Niet alleen de aanwezigheid in het bestuursverslag van de vereiste informatie is object van onderzoek; de accountant zal de kennis die verkregen is bij de controle van de jaarrekening toepassen om te beoordelen of sprake is van materiële onjuistheden. Gezien de ontwikkelingen met betrekking tot het bestuursverslag is dit een goede ontwikkeling. De jaarrekening blijft belangrijk, maar veel andersoortige informatie wordt opgenomen in het bestuursverslag. Voor stakeholders is het van belang dat de accountant, in het kader van de controle van de jaarrekening, hiervoor werkzaamheden verricht en daarover rapporteert.

De minister van Veiligheid en Justitie is van mening dat wanneer een accountant een materiële onjuistheid in het bestuursverslag onderkent die niet aangepast wordt, hij geen goedkeurende verklaring kan afleggen (Tweede kamer, Kamerstukken II, vergaderjaar 2014-2015). Hij stelt dit in relatie tot de controleverklaring bij de jaarrekening. Dit lijkt niet juist. Het oordeel omtrent de jaarrekening en het oordeel omtrent het bestuursverslag kunnen een verschillende strekking hebben. Het kan wel 
zo zijn dat bijvoorbeeld een clausulering met betrekking tot de verklaring bij de jaarrekening van invloed is op het oordeel omtrent het bestuursverslag en vice versa. Ook kunnen onjuistheden in de jaarverslaggeving tot andere reacties van de accountant aanleiding geven, waaronder het teruggeven van de opdracht.

De International Auditing and Assurance Standards Board (IAASB) heeft een herziene standaard 720 (IAASB, 2015) uitgevaardigd, die in Nederland in 2016 van kracht zal worden. Deze herziene standaard wordt reeds in deze paragraaf vermeld, aangezien de huidige ontwikkelingen in Nederland hiermee parallel lopen. Deze standaard behandelt de verantwoordelijkheid van de accountant met betrekking tot andere informatie, hetzij financiële informatie of niet-financiële informatie. Met andere informatie wordt bedoeld: anders dan financiële overzichten en de daarbij behorende controleverklaring. De andere informatie betreft derhalve ook het bestuursverslag. De doelstellingen van de accountant zijn, nadat hij de andere informatie heeft gelezen:

- om te overwegen of er een inconsistentie van materieel belang is tussen de andere informatie en de financiële overzichten;

- om te overwegen of er een inconsistentie van materieel belang is tussen de andere informatie en de kennis van de accountant verkregen in de controle;

- om op passende wijze te reageren wanneer de accountant constateert dat dergelijke inconsistenties van materieel belang lijken te bestaan of wanneer de accountant zich er anderszins van bewust wordt dat andere informatie een afwijking van materieel belang lijkt te bevatten; en

- om overeenkomstig deze standaard te rapporteren. De verantwoordelijkheden van de accountant onder deze standaard vormen geen assurance-opdracht betreffende andere informatie en leggen de accountant geen verplichting op om assurance te verkrijgen over de andere informatie.

Samengevat is de huidige rol van de accountant beperkt tot een toets of bij het lezen van het bestuursverslag sprake is van materiële inconsistentie met de jaarrekening of met de kennis van de accountant verkregen bij de controle van de jaarrekening. Dit betekent dat op grond van de huidige wet- en regelgeving geen assurance bij het bestuursverslag behoeft te worden gegeven. Materiële inconsistenties worden vermeld in de controleverklaring bij de jaarrekening. Vrijwillige assurance-verschaffing is uiteraard wel mogelijk en vindt, zoals later blijkt, reeds plaats.

\section{Toekomstige ontwikkelingen bestuursverslag en assurance}

De werkgroep toekomst accountantsberoep (2014) gaat verder waar het de rol van de accountant en het bestuursverslag (door de werkgroep nog jaarverslag genoemd) betreft. Maatregel 4.3 luidt (deels weergegeven): "De accountant geeft een afzonderlijke beoordelingsverklaring af bij het jaarverslag (zoals bedoeld in art. 2: $391 \mathrm{BW}$ ). In deze beoordelingsverklaring bij het jaarverslag geeft de accountant expliciet zijn oordeel over de risicoparagraaf, de continuïteitsanalyse en corporate governance-informatie zoals opgenomen in het jaarverslag. Indien nodig geeft de accountant een aanvullende reflectie op deze onderwerpen”. De Nederlandse Beroepsorganisatie van Accountants (NBA) heeft de tekst aangepast: in plaats van beoordelingsverklaring wordt gesproken over het ruimere begrip verklaring, zodat ook een controleverklaring kan worden afgegeven. Deze verklaring behoeft ook niet afzonderlijk te zijn van de controleverklaring.

Teneinde een brede groep stakeholders te benaderen heeft de NBA onder meer een drietal activiteiten ontplooid:

- een consultatiedocument (2015);

- een rondetafelbijeenkomst (2016c);

- een position paper (2016d).

De NBA heeft een overzicht consultatiereacties (2016b) op haar website gepubliceerd. In het consultatiedocument waren vijf vragen opgenomen, die betrekking hadden op het bestuursverslag en assurance. Deze vragen zijn:

- wordt van de accountant een apart oordeel over het bestuursverslag verwacht?

- wordt van de accountant een integraal oordeel over de inhoud van het bestuursverslag verwacht?

- moet de accountant over specifieke onderdelen van het bestuursverslag zekerheid verschaffen, zo ja, welke?

- welke mate van zekerheid moet de accountant kunnen geven bij het bestuursverslag of specifieke onderdelen hiervan?

- welke andere voorwaarden zijn nodig om een verklaring van de accountant bij het bestuursverslag mogelijk te maken?

Hierna is integraal de samenvatting van de NBA op de vijf vragen opgenomen.

"De AFM en gebruikers zien geen reden voor een apart oordeel van de accountant over het bestuursverslag. Materiële onjuistheden die in het bestuursverslag worden gesignaleerd moeten in de bestaande controleverklaring worden opgenomen. Zaken als specifieke risico's kunnen als kernpunten van de controle worden opgenomen. Ook door accountants wordt gestreefd naar een in de controleverklaring bij de jaarrekening geintegreerd oordeel over het bestuursverslag. Als belemmeringen worden beschouwd de bestaande verschillen in de normenkaders en aard en omvang van de niet-financiële infor- 
matie en de mate van zekerheid die de accountant kan verstrekken. Ook de opstellers achten een apart oordeel van de accountant over het bestuursverslag onnodig en ongewenst.

Gebruikers verwachten van de accountant in ieder geval een integraal oordeel over de risicoparagraaf, de continuiteitsanalyse en corporate governance informatie. Er zou een mitzondering kunnen worden gemaakt voor bepaalde informatie die buiten het aspect valt van de jaarrekeningcontrole en de kennis die de accountant van de onderneming dient te hebben, zoals de technische omschrijving van producten. Verwacht wordt dat de accountant in ieder geval onderzoek doet naar de robuustheid van het proces van de besluitvorming over de strategie en andere onderdelen. Accountants neigen tot een integraal oordeel over het bestuursverslag.

Gebruikers verwachten dat de accountant een redelijke mate van zekerheid kan geven in ieder geval bij de risicoparagraaf, de continuiteitsanalyse en corporate governance informatie. Ook door accountants wordt gestreefd naar een redelijke mate van zekerheid. Binnen de huidige systematiek kunnen accountants volgens de AFM niet meer dan een beperkte mate van zekerheid verstrekken. Volgens de AFM is voor een volgende stap naar geïntegreerde verslaggeving een meer fundamentele wijziging nodig in zowel verslaggevingsstandaarden als controlestandaarden”.

De passage dat accountants neigen tot een integraal oordeel over het bestuursverslag, staat tegenover het vermelden van alleen specifieke onderdelen, zoals de risicoparagraaf, de continuïteitsanalyse en corporate governance-informatie. Gezien de ontwikkelingen met betrekking tot de verslaggeving, waaronder integrated reporting, is deze reactie begrijpelijk. De nadere uitwerking verdient nog de nodige aandacht.

Twee vragen hadden betrekking op niet-financiële informatie in het bestuursverslag.

Deze vragen zijn:

- komen de aan de inhoud van het bestuursverslag gestelde eisen tegemoet aan de verwachtingen van aandeelhouders en andere gebruikers?

- in hoeverre moeten er meer eisen worden gesteld aan de inhoud van het bestuursverslag met betrekking tot respectievelijk de risicoparagraaf, continuïteitsanalyse, corporate governance-informatie en niet-financiële informatie.

"Gebruikers hechten veel waarde aan een controle van de in het bestuursverslag opgenomen niet-financiële informatie. Ook de AFM acht een onafhankelijke toetsing wenselijk waarbij een controle door een andere deskundige dan de accountant niet voor de hand ligt. Gebruikers verwachten dat de accountant in ieder geval materiële discrepanties met de door hem of haar vast te stellen feitelijke gang van zaken binnen de onderneming moet kunnen signaleren. Waar nodig zou de accountant voor de controle van desbetreffende informatie moeten samenwerken met andere materiedeskundigen. Accountants achten zich met in achtneming van het voorgaande in staat om een oordeel te geven over in ieder geval de wijze waarop de betreffende informatie tot stand komt".

In 2016 dient de EU-richtlijn (2014/95/EU) bekendmaking van niet-financiële informatie en informatie inzake diversiteit door bepaalde grote ondernemingen en groepen in boek 2 BW te zijn geïmplementeerd. De minister van Veiligheid en Justitie maakt geen gebruik van de optie om de desbetreffende informatie te laten controleren door een onafhankelijke dienstverlener van assurancediensten. Hij volstaat met een zogenoemde aanwezigheidstoets. Dit spoort niet met de reacties in het consultatiedocument.

De AFM en gebruikers verwachten van internal auditors een waardevolle bijdrage bij het door de accountant te verschaffen niveau aan zekerheid. Tevens zien zij een rol voor de externe accountant weggelegd bij integrated reporting.

Ook van de rondetafelbijeenkomst is een verslag (NBA, 2016c) op de website van de NBA geplaatst. Naast inleidingen vond discussie plaats aan de hand van stellingen. Ter zake van het bestuursverslag en assurance zijn onder meer de volgende opmerkingen gemaakt:

- gebruikers wensen dat wordt gewerkt met één controleverklaring waarin de accountant een hoge mate aan zekerheid geeft, die thans in de controleverklaring omschreven wordt met de woorden redelijke mate van zekerheid;

- de deelnemers konden zich vinden in de stelling dat de accountant een redelijke mate van zekerheid kan verstrekken bij zijn oordeel over de risicoparagraaf, de continuiteitsanalyse en corporate governance-informatie;

- met betrekking tot toekomstgerichte informatie zou de accountant niet alleen een oordeel over het proces van totstandkoming kunnen geven, maar ook over de kwaliteit van de informatie;

- opgemerkt werd dat als een interne auditor aanwezig is, van zijn werkzaamheden gebruik gemaakt moet worden;

- een slotopmerking was dat moet worden gestreefd naar een vorm van positieve assurance bij financiële en niet-financiële informatie.

Het position paper "Een relevant en betrouwbaar bestuursverslag” (NBA, 2016d) is eveneens via de website te benaderen. Een drietal conclusies wordt integraal weergegeven:

"- de NBA pleit voor het stellen van eisen aan het bestuursverslag die zijn gericht op het door ondernemingen opnemen van voor de gebruikers relevante informatie. Volgens de NBA moet ook de niet-financiële informatie zoals bedoeld in richtlijn 
2014/95/EU onderdeel zijn van het bestuursverslag. Ook hiervoor moet gelden dat de accountant nagaat of de informatie verenigbaar is met de jaarrekening en of er sprake is van materiële onjuistheden;

- met ingang van de boekjaren die beginnen op of na 1 januari 2016 moet de accountant verklaren of hij materiële onjuistheden in het bestuursverslag heeft vastgesteld. De NBA geeft in 2016 in de eigen beroepsreglementering een nadere duiding van de werkzaambeden die op dit terrein van de accountant worden verwacht;

- de NBA zet zich ervoor in dat gebruikers zoveel mogelijk moeten kunnen vertrouwen op de inhoud van het bestuursverslag en het onderzoek hiervan door de accountant. De NBA wil voor beursgenoteerde ondernemingen binnen vier jaar een oordeel over het bestuursverslag in de controleverklaring verwezenlijken. De NBA start binnenkort een project om te onderzoeken welke voorwaarden hiervoor nodig zijn”.

In internationaal verband heeft de Integrated Reporting Working Group van de IAASB een discussion paper "Supporting Credibility and Trust in Emerging Forms of External Reporting (EER): Ten Key Challenges for Assurance Engagements" (2016) gepubliceerd. Het lezenswaardige paper gaat na een goede analyse in op de Ten Key Challenges in Relation to EER Assurance Engagements:

scoping EER assurance engagements;

- suitability of criteria;

- materiality;

- building assertions in planning and performing the engagement;

- maturity of governance and internal control processes;

- narrative information;

- future-oriented information;

- professional skepticism and professional judgment;

- competence of practitioners performing the engagement;

- form of the assurance report.

Op deze plaats wordt niet nader op het paper ingegaan.

De tien "uitdagingen" geven aan dat nog het nodige werk verzet moet worden om tot goede ondersteuning van de professionals te komen.

In mijn afscheidscollege "Panta rhei 2" (Gortemaker, 2016) besteedde ik aandacht aan ontwikkelingen op het gebied van assurance, mede gericht op het bestuursverslag en integrated reporting. Bijzondere aandacht besteedde ik aan het te bereiken niveau aan zekerheid en de daarbij behorende formulering. De huidige twee niveaus van zekerheid: redelijke mate van zekerheid en beperkte mate van zekerheid, waarbij de hoeveelheid werkzaamheden de bepalende factor vormt, schieten naar mijn mening tekort (zie ook Gortemaker, 2001). Bij de ontwikkeling van het Stramien voor Assurance-opdrachten (NV COS, 2016) was ove- rigens een meerderheid van de leden van de IAPC (thans IAASB), waaronder ondergetekende, van mening dat vier variabelen: de aard van het object, de toegepaste criteria, de aard en omvang van het assuranceproces en de kwaliteit van het bewijsmateriaal het te bereiken niveau bepalen. Ook aan de huidige formulering van de niveaus van zekerheid dient aandacht geschonken te worden. Ik pleit voor een zogenoemd longform rapport bij assurance-opdrachten, waarin op basis van professionele oordeelsvorming de conclusie wordt weergegeven, zonder gehouden te zijn aan standaardbewoordingen. De hiervoor genoemde vier variabelen bepalen de bewoordingen die passen bij het gerealiseerde niveau van zekerheid.

\section{Huidige praktijk}

Een aantal (grote) ondernemingen laat reeds op vrijwillige basis assurance verschaffen aan informatie opgenomen in de jaarverslaggeving naast de vereiste controle van de jaarrekening. Hierbij tekent zich een grote variëteit aan qua scope van de informatie waarop de assurance-verschaffing betrekking heeft en van de verschafte niveaus van zekerheid. Een onderzoek naar de toepassing van integrated reporting (Hurks et al., 2015) geeft een beeld van de aanwezigheid van een assurance opinion bij een integrated report. Van de 38 geselecteerde ondernemingen namen 21 (55\%) een assurance opinion bij het integrated report op. Bij 3 (14\%) verslagen verschafte de accountant een redelijke mate van zekerheid; in 14 (67\%) situaties was sprake van een beperkte mate van zekerheid en in 4 verklaringen werd zowel een redelijke mate als een beperkte mate van zekerheid verschaft. De voorzitter van het Adviescollege voor Beroepsreglementering van de NBA meldde tijdens de eerder genoemde rondetafelbijeenkomst dat in 2014 van de 50 grootste ondernemingen, 23 (46\%) een vorm van assurance bij het bestuursverslag kenden. In de meeste gevallen was sprake van een beperkte mate van zekerheid, maar een redelijke mate van zekerheid kwam ook voor. Ook de vorm van de accountantsrapportage varieert van een afzonderlijk assurance-rapport, een combinatie van een controleverklaring en een assurance-rapport tot een volledig geïntegreerd rapport. Een voorbeeld van een meer geintegreerde accountantsrapportage is het Combined Independent Auditor's Report on the Financial Statements 2015 and sustainability information in KPN's Integrated Annual Report 2015 (KPN, 2015).

\section{Slotbeschouwing}

Het bestuursverslag neemt een steeds belangrijker plaats in binnen het geheel van de jaarlijkse verslaggeving. Wet- en regelgeving, codes, maar ook ontwikkelingen met betrekking tot integrated reporting dragen hiertoe bij. Tot voor kort beperkte de betrokkenheid van de accountant bij het bestuursverslag zich tot de 
zogenoemde aanwezigheids- en consistentietoets. De huidige betrokkenheid vereist, dat de accountant de kennis die verkregen is bij de controle van de jaarrekening, zal toepassen om te beoordelen of sprake is van materiële onjuistheden. Gezien de toenemende betekenis van het bestuursverslag is dit een goede ontwikkeling. Diverse stakeholders pleiten voor een vorm van zekerheid (assurance) bij het bestuursverslag. Teneinde hier meer zicht op te krijgen heeft de NBA in 2015 en 2016 activiteiten ontplooid. Het consultatiedocument, de rondetafelbijeenkomst en het position paper leveren een goede bijdrage voor de toekomstige ontwikkelingen op het gebied van assurance-verschaffing bij het bestuursverslag. Het te bereiken niveau van ze- kerheid, de factoren die het niveau beïnvloeden, alsmede de formulering behoeven aandacht. Op dit moment laten veelal grote ondernemingen op vrijwillige basis reeds assurance verschaffen bij het bestuursverslag.

Prof. J.C.A. Gortemaker RA is hoogleraar audit en assurance aan de Erasmus Universiteit Rotterdam. Daarnaast vervult hij bestuurlijke en toezichthoudende functies. Vele jaren was hij lid van (inter)nationale commissies op het gebied van audit en assurance waaronder de IAPC, thans IAASB geheten. Bij de IAPC was hij betrokken bij het ontwikkelen van het zogenoemde assurance framework.

\section{Literatuur}

a Europese Unie (EU)(2013). Richtlin 2013/34/ EU van het Europees parlement en van de Raad van 26 juni 2013 betreffende de jaarlijkse financiële overzichten, geconsolideerde financiële overzichten en aanverwante verslagen van bepaalde ondernemingsvormen, tot wijziging van Richtlijn 2006/43/EG van het Europees Parlement en de Raad en tot intrekking van Richtlijnen 78/660/EEG en 83/349/ EEG van de Raad.

- Europese Unie (EU)(2014). Richtlijn 2014/95/ EU van het Europees Parlement en de Raad van 22 oktober 2014 tot wijziging van richtlijn 2013/34/EU met betrekking tot de bekendmaking van niet-financiële informatie en informatie inzake diversiteit door bepaalde grote ondernemingen en groepen.

- Gortemaker, J.C.A. (2001). International Standard on Assurance Engagements. Maandblad voor Accountancy en Bedrijfseconomie, 75(3).

- Gortemaker, J.C.A. (2016). Panta rhei 2. Afscheidsrede Erasmus Universiteit Rotterdam. Verkrijgbaar via Erasmus Universiteit, secretariaat Acccountancy.

- Hurks, P.F.M., Langendijk, H.P.A.J., \& Nandram, P.K. (2015). How do public Integrated Reports align with the $<\mathbb{R}>$ Framework. Maandblad voor Accountancy en Bedriffseconomie, 89(12): 518-532.

- International Auditing and Assurance Standards Board (IAASB, 2015). International Standard on Auditing 720 (Revised): The auditor's responsibilities relating to other information (effective for audits of financial statements for periods ending on or after december 15, 2016).

- International Federation of Accountants, New York.International Auditing and Assurance Standards Board (IAASB, 2016). Supporting Credibility and Trust in Emerging Forms of External Reporting: Ten Key Challenges for Assurance Engagements. International Federation of Accountants, New York. Geraadpleegd op https://www.ifac.org/system/files/ publications/files/AAASB-Discussion-Paper-Integrated-Reporting_0.pdf. Supplemental information. Geraadpleegd op https://www.ifac. org/system/files/publications/files/AAASB-Discussion-Paper-Integrated-Reporting-Supplemental-Information_0.pdf.

- Knoops, C.D. (2004). Het jaarverslag en de Overige gegevens. In M.N. Hoogendoorn, J. Klaassen en F. Krens, Externe verslaggeving in theorie en praktijk, vierde druk (pp. 11961256). 's-Gravenhage: Reed Business Information b.v.

- Koninklijke KPN N.V. Jaarverslag 2015. http:// www.kpn.com/jaarverslag.Monitoring Commissie Corporate Governance Code (2008). Nederlandse Corporate Governance Code (2008). Geraadpleegd op http://www.commissiecorporategovernance.nl/ download/?id=609.

- Monitoring Commissie Corporate Governance Code (2016). Nederlandse Corporate Governance Code, Voorstel voor herziening (2016). Geraadpleegd op http://www. estibbe.com/ corpgov/documenten/Consultatiedocument\%20Code.pdf.

- Nederlandse Beroepsorganisatie van Accountants (NBA, 2016a). Nadere voorschriften con- trole- en overige standaarden (NV COS). Handleiding Regelgeving Accountancy 2016. Geraadpleegd op https://www.nba.nI/Wet-enregelgeving/Beroepsregels/HRA/.

- Nederlandse Beroepsorganisatie van Accountants (NBA, 2016b). Overzicht reacties NBA consultatie 'De accountant en het bestuursverslag; verder kijken dan de jaarrekening'. Geraadpleegd op https://www.nba.n//Documents/Consultatiereacties\%202016/Consultatiereacties_De_accountant_en_het $\% 20$ bestuursverslag/Overzicht\%20consultatiereacties\%20De\%20accountant\%20en\%20 het\%20bestuursverslag.pdf.

- Nederlandse Beroepsorganisatie van Accountants (NBA, 2016c). Verslag NBA Ronde tafel 'Relevantie en zekerheid; Discussie over de accountant en het bestuursverslag'. Geraadpleegd op https://www.nba.n//Documents/ Consultatiereacties\%202016/Consultatiereacties_De_accountant_en_het\%20bestuursverslag/Nerslag_rondetafel_Accountant_en_ bestuursverslag.pdf

- Nederlandse Beroepsorganisatie van Accountants (NBA, 2016d). Positon paper 'Een relevant en betrouwbaar bestuursverslag'. Geraadpleegd op https://www.nba.nl/ Documents/Nieuws/Persberichten/NBA_Position_paper-Een_relevant_\%20en_betrouwbaar_bestuursverslag.pdf.

- Nederlandse Beroepsorganisatie van Accountants (NBA, 2015). Consultatiedocument 'De accountant en het bestuursverslag: verder kijken dan de jaarrekening'. Geraadpleegd op https://www.nba.nl/Documents/Wet-\%20 en\%20Regelgeving/Gedrags-\%20en\%20 
beroepsregels/Consultaties/NBA_Nota\%20 Accountant $\% 20$ en\%20Bestuursverslag\%20 WEB.pdf.

- Raad voor de Jaarverslaggeving (2015). Richtlijnen voor de Jaarverslaggeving, editie 2015. Deventer: Kluwer.

- The International Integrated Reporting Council (IIRC, 2013). Integrated Reporting (2013). IRC.

- Tweede Kamer der Staten-Generaal (2015). Kamerstukken II, Vergaderjaar 2014-2015, 34
176 Nr. 6. Geraadpleegd op https://zoek.officielebekendmakingen.nI//kst-34176-6.html.

- Uitvoeringswet richtlijn jaarrekening (2015). Staatsblad van het Koninkrijk der Nederlanden, jaargang 2015.

- Vaststellingsbesluit nadere voorschriften inhoud bestuursverslag (2015). Staatsolad van het Koninkrijk der Nederlanden, jaargang 2015.

- Werkgroep toekomst accountantsberoep (Brouwer, A.J., Clement, D., Van Es, N., Jon- geneel, T., Lauret, M-P., Saasen, P-P., \& Segers, C.) (2014). In het publiek belang Maatregelen ter verbetering van de kwaliteit en onafhankelijkheid van de accountantscontrole. Werkgroep Toekomst Accountantsberoep, Amsterdam. Geraadpleegd op https:// www.nba.n/Documents/Nieuws/2014/pdfs/ In\%20het\%20publiek\%20belang\%20rapport\%20WG\%20Toekomst\%20Acc\%20 25sep14.pdf. 